\title{
Assessment of Patient Satisfaction with Pharmaceutical Services in Ministry of Health Hospitals at East Province, Saudi Arabia
}

\author{
Mohammed Mohsen Almaznai ${ }^{1}$, Osama Mohammed Almadani², Ibrahim Abdul Karim Aloraifi ${ }^{3}$, Saleh \\ Ali Alsallouk ${ }^{4}$, Hussain Alkabaz ${ }^{5}$, Abdulaziz Saud Alotaibi ${ }^{5}$, \\ Hamdi Abdullah Alamri ${ }^{5}$, Kairat Imad Al-Hennawi ${ }^{6}$, Mohanad Imad Al-Hennawi ${ }^{6}$, Yousef Ahmed \\ Alomi $^{7, *}$ (D) \\ ${ }^{1}$ Director of Pharmaceutical Care Administration in Eastern Province Health, SAUDI ARABIA. \\ ${ }^{2}$ Head of Forensic Medicine in Eastern Province, SAUDI ARABIA. \\ ${ }^{3}$ General Manager of Regional Health Affairs in Eastern Province, SAUDI ARABIA. \\ ${ }^{4}$ Advisor of Director of Dammam Medical Complex, SAUDI ARABIA. \\ ${ }^{5}$ Pharmacy Staff, Pharmaceutical Care Administration in Eastern Province, SAUDI ARABIA. \\ ${ }^{6}$ Clinical Pharmacist Staff, General Administration of Pharmaceutical Care, Ministry of Health, Riyadh, SAUDI ARABIA. \\ ${ }^{7}$ The Former General Manager of General Administration of Pharmaceutical Care, Former Head, National Clinical \\ Pharmacy and Pharmacy Practice, Former Head, Pharmacy R and D Administration, Ministry of Health, Riyadh, \\ SAUDI ARABIA.
}

\begin{abstract}
Objective: Patient satisfaction is considered as a measure of the quality of care in health system. Investigation of satisfaction with pharmaceutical services will disclose gaps in training and barricades of implementation. The study examined patient satisfaction of pharmaceutical services at Ministry of Health Hospitals at East Province in Saudi Arabia. Methods: It is a 4-months cross-sectional self-administered survey of patient satisfaction of pharmaceutical care in Ministry of Health Hospitals at East Province, Saudi Arabia. The survey comprises two parts; the first part was demographic data about the patients, the second part was several domains about various pharmaceutical care services at East Province in Saudi Arabia. The 5-point Likert response scale system used with closed and ended questions. The survey scattered through five hospitals in East Province involved a public, pediatrics, maternity and psychiatry hospitals ambulatory care patient. All data and variables analyzed by Microsoft Excel program version 10. Results: The study sample size was 892 . Out of 892 patients, 815 (95.66\%) was Saudi and 37 (4.34\%) was non-SaudiSaudi. Of that 213 (25\%) was female and $639(75 \%)$ was male. The majority of patients were between the ages of $20-40(61.33 \%)$ and $41-60$ years $(39.44 \%)$ old. The average score of pharmacy location and related issues was 3.69/5.00. The domain of pharmacy location was ranked highest (4.05/5.00), while the domain of pharmacy waiting area was ranked lowest (3.47/5.00). The average score of medication related issues was $4.28 / 5.00$. The domain of the drug label stickled with all medications was ranked highest (4.43/5.00), while the domain of the medication reconciliation was ranked lowest (3.56/5.00). The average score of pharmacist related issues was $4.66 / 5.00$. The domain of the pharmacist assure by your name before dispensing was ranked highest (4.58/5.00), while the domain of the pharmacist provides you with medication counseling and encourages you to ask questions was ranked lowest (3.91/5.00). The overall pharmacy evaluation was 4.55/5.00. Conclusion: The patient satisfaction of pharmacy services was adequate at $\mathrm{MOH}$ hospital in East Province, Saudi Arabia. The outcomes showed a lack in pharmacists 'interaction with patients and exertions should be focused towards involvement in a more patient-oriented training in Saudi hospital pharmacies.

Key words: Assessment, Patient, Satisfaction, Pharmaceutical, Services, Ministry of Health, East Province, Saudi Arabia.
\end{abstract}

Received: 11-11-2018

Accepted: 10-01-2019

${ }^{*}$ Correspondence to:

Dr. Yousef Ahmed Alomi

The Former General Manager of Genera Administration of Pharmaceutical Care, Former Head, National Clinical Pharmacy and Pharmacy Practice, Former Head, Pharmacy R and D Administration, Ministry of Health, P.O.BOX 100, Riyadh 11392, Riyadh, SAUDI ARABIA.

Phone no: +966504417712

Email: yalomi@gmail.com

DOI: 10.5530/ijpcs.2019.8.20

Copyright: ๑ the author(s),publisher and licensee International Journal of Pharmacology and Clinical Sciences. This is an open-access article distributed under the terms of the Creative Commons Attribution Non-Commercial License, which permits unrestricted noncommercial use, distribution, and reproduction in any medium, provided the original work is properly cited.

This is an open access article distributed under the terms of the Creative Commons Attribution-NonCommercial-ShareAlike 4.0 License

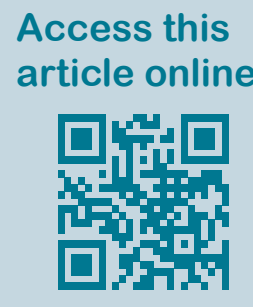

www.ijpcs.net 


\section{INTRODUCTION}

Patient satisfaction is an important humanistic evidence to determine the consequence, assists and sustainability of any health care system. It is also a dynamic tool to monitor the advancement and quality improvement in health care delivery systems. Pharmaceutical service is an integral part of the health care system that establish a set of services delivered by pharmacists to patients. Pharmacists have a variety of responsibilities including managing patients' medications, following up with patients and educating patients about adverse effects. ${ }^{[1]}$ Patient's satisfaction is essential as it has an impact on patients' health according to a study published by Kristel Lobo Prabhu and his colleagues. ${ }^{[2]}$ Strand LM and his colleagues showed that better service quality would result in serving supplementary patients with an increase in time spent with each patient. ${ }^{[3]}$ The pharmacy services expanded over the past several years in the East Province, Saudi Arabia. Due to difference in performance of community pharmacies, the patients' need, insight and satisfaction level also speckled in developing country. The expansion was done through regional pharmacy administration at medical Affairs of Ministry of Health. The pharmacy administration implemented a strategic plan for five years. The administration followed up the plan through measuring patient's satisfaction of pharmacy services in the East Province, Saudi Arabia.

Patient satisfaction studies are beneficial for drawing a baseline when beginning new strategies. Consequently, the patient's satisfaction was essential to measure the quality of services provided by health care workers. ${ }^{[4]}$ Therefore, the ministry of health in Saudi Arabia has added patient satisfaction of pharmaceutical service as one of the standards follow up measures. ${ }^{[5]}$ There are many factors affecting patients' satisfaction including waiting time, medication availability, providing storage information, explaining side effects, in addition to sociocultural factors. ${ }^{[6]}$ Many studies have been conducted worldwide to evaluate patient satisfaction toward community pharmacy services. ${ }^{[7-11]}$ More satisfied patients are determined in using health care services and values. However, data regarding patients' satisfaction of pharmaceutical services are inadequate in Saudi Arabia compared to western countries.

Moreover, sociocultural factors might effect the results. Therefore, more studies is needed to improve the quality of pharmaceutical services provided. ${ }^{[6]}$ The most of the studies commenced the patient satisfaction of pharmacy at either one hospital and not exceed three hospitals at the same time. The administration did the most wideranging survey of pharmacy patient satisfaction in the region and even in the county. They executed the tool of patient satisfaction over five biggest hospitals at the same time. This work signifies the first exertion in the field to assess patient's satisfaction with practices and services.

\section{METHODS}

This is a 4-months cross-section survey of patients' satisfaction of pharmacy services, was conducted at five Ministry of Health Hospitals in Saudi Arabia. The Maternity and Children Hospital with 500 beds. Dammam Medical Complex is consisted of 340 beds. General Jubail Hospital is consisted of 200 beds. Al-Qatif Central Hospital is formed of 345 beds. Al-Alamal Complex for Mental Health is formed of 300 beds. This study consists of two parts with twenty-four (24) questions: the first part captures demographic information and the second part consisted of three domains included pharmacy location related issues, medication-related issues, pharmacist related issues. The 5-point Likert response scale system was used with closed and ended questions. The survey distributed through five hospitals in East Province included a public, pediatrics, maternity and psychiatry hospitals ambulatory care patients during study period.

All the hospitals accredited by Saudi Center Board for Healthcare Hospital Accreditation. The hospital provides clinical services in adults and neonatal critical care, emergency and ambulatory care services. The hospital had very large specialized ambulatory care clinic with different specialties and inside hospital including medical and surgical and pediatrics. The hospital had pharmaceutical care department with 24/7 coverage. It consisted of inpatient pharmacy, ambulatory care and emergency pharmacies in addition to the drug information center and medication safety services. The pharmacy operated through Computerized Physician Order Entry (CPOE) cross the hospital department and units. The Microsoft Excel sheet version 10.0 was used for data entry and analysis. The study was conducted according to the ethics guidelines set out in the Declaration of Helsinki and written consent from was obtained from the institution. 


\section{RESULTS}

The study sample size was 892 . Out of 892 patients, 815 (95.66\%) was Saudi and 37 (4.34\%) was non-SaudiSaudi. Of that $213(25 \%)$ was female and 639 (75\%) was male. The majority of patients were between the ages of 20-40 (61.33\%) and $41-60$ years (39.44\%) old. The most educational level of the responders was high school or lower 337 (39.55\%), Bachelor degree and above 293 (34.39\%) and diploma level was 175 (20.54\%) (Table 1). The patients' satisfaction questionnaire was grouped into 3 sub-scales: Pharmacy location related issues, Medications-related issues and Pharmacistrelated issues.

The average score of pharmacy location and related issues was 3.69/5.00. The domain of pharmacy location was ranked highest (4.05/5.00), while the domain of pharmacy waiting area was ranked lowest (3.47/5.00). The average score of other domains were 3.58 (the privacy counseling area), 3.69 (pharmacy waiting time) and 3.71 (overall pharmacy evaluation). The average score of medication related issues was 4.28/5.00. The domain of the drug label stickled with all medications was ranked highest (4.43/5.00), while the domain of the medication reconciliation was ranked lowest (3.56/5.00). The average score of other domains were 3.88 (received all medications in the prescription), 4.34 (the drug label had completed an instructions), 3.57 (providing of adverse drug reaction information) and 3.63 (providing of drug storage information). The average score of pharmacy related issues was 4.66/5.00. The domain of the pharmacist assure by your name before dispensing was ranked highest (4.58/5.00), while the domain of the

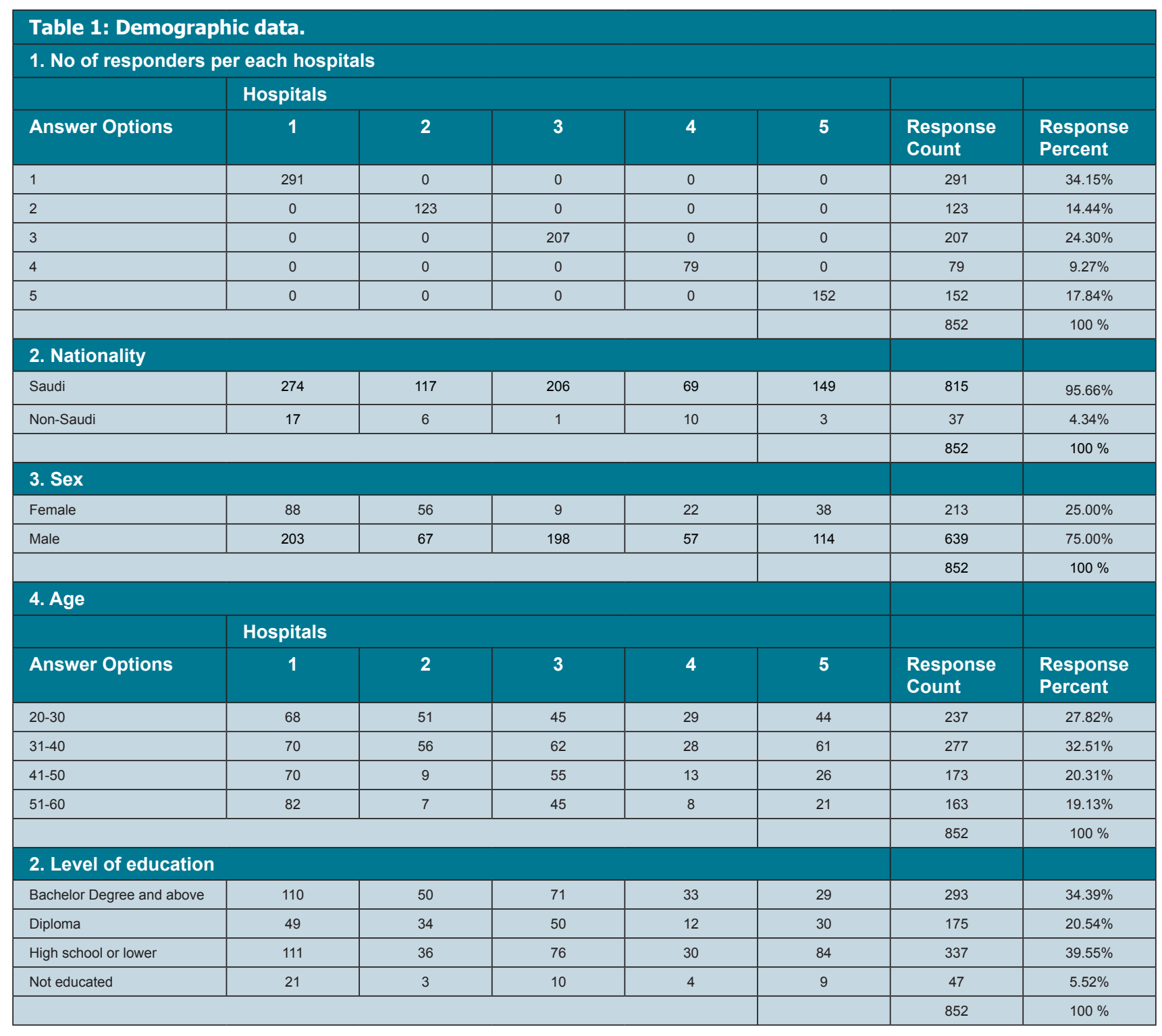


pharmacist provides you with medication counseling and encourages you to ask questions was ranked lowest (3.91/5.00). The average score of other domains were 4.47 (understand what pharmacist saying), 3.95 (the amount of time the pharmacist spends with you) and 4.39 (all pharmacists characterized with courtesy and respect). The overall pharmacy evaluation was 4.55/5.00 (Table 2).

\section{DISCUSSION}

Quality enhancement is vital for improvement in health care systems. It is envisioned that through regular tracking of dimensions of quality of care, health providers and hospitals could receive timely response on areas of deficiency paving the way to rouse a mechanism to improve patient satisfaction. Over the past fifteen years, the regional Pharmacy administration in medical affairs at East Province was established. There were several achievements including pharmacy administration Skelton with several sections, clinical pharmacy section, pharmacy human resources, medication safety officer and regional drug information center. The pharmacy management started with several pharmacy practices and clinical pharmacy programs including pharmacy strategic plan, medications safety program, patient counseling program, pharmacy clinic and several measurement tools to follow up pharmacy plan where to determine some facets of patient's attitude and satisfaction of pharmaceutical services provided by the pharmacist. ${ }^{[5,12]}$ The regional pharmacy administration conducted a study to explore the patient satisfaction of ambulatory care services over the well-known biggest hospital in the East Province area. Satisfaction differs based on the patient level of education and exposure. The survey contained of three parts: Pharmacy location related issues, medications related factors and pharmacist associated issues. A fourmonths period survey was conducted to assess patients' satisfaction of pharmaceutical services at the ministry of health hospitals at East Province in Saudi Arabia. The survey focused on demographic factors, medicationrelated factors and pharmacist related factors. More than eight hundred patients participated in the survey from five hospitals which is an adequate number of participants compared to other studies. ${ }^{[4,7,10,13]}$ The survey was planned base on several criteria such as law indicators, standard indicators, policy indicators, medication safety indicators, patient outcome indicators and customer needs indicators. Most of the participants were Saudis as only a small portion of non-Saudis are permissible to receive health services at the ministry of health hospitals. The majority of the participants were male might be due to cultural factors which are similar

\section{Table 2: Patient satisfaction Parts.}

\begin{tabular}{|c|c|c|c|c|c|c|}
\hline \multirow[b]{2}{*}{ Answer Options } & \multicolumn{5}{|c|}{ Hospital average scores } & \multirow[b]{2}{*}{$\begin{array}{l}\text { Rating } \\
\text { Average }\end{array}$} \\
\hline & 1 & 2 & 3 & 4 & 5 & \\
\hline \multicolumn{7}{|l|}{ 1. Pharmacy location related issues } \\
\hline Pharmacy location & 3.85 & 4.40 & 3.63 & 4.67 & 4.41 & 4.05 \\
\hline Pharmacy waiting area & 3.14 & 4.05 & 2.93 & 4.22 & 4.02 & 3.47 \\
\hline The privacy counseling area & 3.53 & 3.51 & 2.89 & 4.40 & 4.22 & 3.58 \\
\hline Pharmacy waiting time & 3.62 & 4.24 & 2.62 & 4.62 & 4.40 & 3.69 \\
\hline Overall pharmacy evaluation & 3.75 & 4.11 & 3.20 & 4.51 & 4.55 & 3.71 \\
\hline \multicolumn{7}{|l|}{ 2. Medications-related issues, } \\
\hline Received all medications in the prescription & 3.73 & 3.82 & 3.46 & 4.62 & 4.40 & 3.88 \\
\hline The drug label stickled with all medications & 4.58 & 3.95 & 4.50 & 4.41 & 4.46 & 4.43 \\
\hline The drug label had complete an instructions & 4.46 & 3.80 & 4.50 & 4.40 & 4.30 & 4.34 \\
\hline Providing of adverse drug reaction information & 3.49 & 3.40 & 3.11 & 4.20 & 4.15 & 3.57 \\
\hline The medication reconciliation & 3.51 & 3.33 & 3.03 & 4.32 & 4.15 & 3.56 \\
\hline Providing of drug storage information & 3.48 & 3.46 & 3.15 & 4.47 & 4.25 & 3.63 \\
\hline \multicolumn{7}{|l|}{ 3. Pharmacist-related issues } \\
\hline $\begin{array}{l}\text { The pharmacist provides you with thorough medication } \\
\text { counseling and encourages you to ask questions. }\end{array}$ & 3.76 & 3.90 & 3.40 & 4.76 & 4.44 & 3.91 \\
\hline You understand what pharmacist saying & 4.39 & 4.39 & 4.25 & 4.82 & 4.79 & 4.47 \\
\hline The amount of time the pharmacist spends with you. & 3.86 & 4.33 & 3.19 & 4.62 & 4.49 & 3.95 \\
\hline All pharmacists characterized with courtesy and respect & 4.34 & 4.36 & 3.82 & 4.78 & 4.79 & 4.39 \\
\hline The pharmacist assure by your name before dispensing & 4.59 & 4.41 & 4.44 & 4.76 & 4.81 & 4.58 \\
\hline
\end{tabular}


to another study in Saudi Arabia as females tend to not take part in specific research and questionnaires. ${ }^{[14]}$ Majority of patients were middle-aged as they have fewer complications accessing health care services related to old aged patients.

The most patient satisfied with pharmacist related issues more than medications and pharmacy location. Pharmacists are the most trusted and accessible health professional. They are always accessible to render their legal duty of dispensing, clerking patients and giving drug evidence to patients. They had good communication skills and distributed medicines in proper manner where the pharmacy design and location did not reach to optimal level because the pharmacy did not build based on the international standards. Pharmacists are always available to answer questions from patients and other health care professionals; regarding drugs use and their health. ${ }^{[4,10]}$

Despite the high satisfaction of pharmacist related factors, the worst point was patient counseling factor related to systemic patient counseling program not yet conventional during conducting of the study. With the findings of medication factors, the worst points were medication reconciliation and adverse drug reaction. Both of the elements were not well determined at most the study hospitals. Medication labeling, counseling, reconciliation and providing the patient with complete drug information was high compared to other studies. Encouraging patients to ask questions makes sense; this is may be due to the high number of patients which lead to decrease the time available for each patient. However, they are still in the range of other national and international studies. ${ }^{[4,10]}$ The worst part was pharmacy location issues with an emphasis on pharmacy waiting area and privacy of counseling place. Both of them need to be revised. Impact of waiting time on patient satisfaction and waiting area also serves international range according to the study conducted in Singapore. ${ }^{[8]}$ The study showed that some socio-demographic variables have substantial different result on satisfaction. Males were found to be more fulfilled with overall pharmaceutical services than females. The overall patient satisfaction of pharmacy services was acceptable and better than what reported with local studies. The pharmacy services seem better than other institutions where almost equal to international pharmacy services. ${ }^{[9-10,15]}$ Based on the findings, the Pharmacy administration can review the Pharmacy strategic plan and start according to priorities and patient demand. It is more important to improving the health care services in hospitals in Saudi Arabia. This could be elucidated by the fact that in this category the maximum satisfaction level is less than those of higher education who typically expects very high standard of amenities.

\section{CONCLUSION}

Pharmaceutical services were found to be within an adequate level of satisfaction. Patient satisfaction with pharmaceutical care system is a crucial tool to follow up the execution of strategic planning of General Administration of Pharmaceutical Care in Saudi Arabia. The patient satisfaction of ambulatory care pharmacy services was acceptable. Pharmacy staff (particularly clinical pharmacists) should be more involved in patient counseling. The annual or every two years survey of pharmacy satisfaction tool is required at $\mathrm{MOH}$ hospital, East province in the Kingdom of Saudi Arabia.

\section{ACKNOWLEDGEMENT}

None.

\section{CONFLICT OF INTEREST}

The authors declare no conflict of interest.

\section{ABBREVIATIONS}

CPOE: Computerized Physician Order Entry; MOH: Ministry of Health; KSA: Kingdom of Saudi Arabia.

\section{ORCID ID}

Yousef Ahmed Alomi (D, https://orcid.org/0000-0003$1381-628 \mathrm{X}$

\section{REFERENCES}

1. Buxton JA, Babbitt R, Clegg CA, Durley SF, Epplen KT, Marsden LM, et al. ASHP guidelines: Minimum standard for ambulatory care pharmacy practice. Am J Heal Pharm. 2015;72(14):1221-36.

2. Lobo PK, Cleghorn MC, Elnahas A, Tse A, Maeda A, Quereshy FA, et al. Is quality important to our patients? The relationship between surgical outcomes and patient satisfaction. BMJ Qual Saf. 2018;27(1):48-52.

3. Strand LM, Cipolle RJ, Morley PC, Frakes MJ. The impact of pharmaceutical care practice on the practitioner and the patient in the ambulatory practice setting: twenty-five years of experience. Curr Pharm Des. 2004;10(31):3987-4001.

4. Alomi YA, Kurdy L, Aljarad Z, Basudan H, Almekwar B. Patient satisfaction of pharmaceutical care of primary care centers at Ministry of Health in Saudi Arabia. J Pharm Pract Community Med. 2016;2(3):79-87.

5. Alomi YA, Alghamdi SJ, Alattyh RA. Strategic plan of general administration of pharmaceutical care at Ministry of Health in Saudi Arabia 2012-2022. J Pharm Pharm Scien. 2015;1(13):1-8. 
6. Abolfotouh MA, Al-Assiri MH, Alshahrani RT, Almutairi ZM, Hijazi RA, Alaskar AS. Predictors of patient satisfaction in an emergency care centre in central Saudi Arabia: A prospective study. Emerg Med J. 2017;34(1):27-33.

7. Oparah AC, Kikanme LC. Consumer satisfaction with community pharmacies in Warri, Nigeria. Res Soc Adm Pharm. 2006;2(4):499-511.

8. Tam VHY, Lim MM. Patients' perceptions and expectations of outpatient pharmacy services in a teaching hospital. Int J Pharm Pract. 1997;5(3):128-32.

9. Al-Arifi MN. Patients' perception, views and satisfaction with pharmacists' role as health care provider in community pharmacy setting at Riyadh, Saudi Arabia. Saudi Pharm J. 2012;20(4):323-30.

10. Al-Jumah KA, Hassali MA, Al-Zaagi I. Adaptation and validation of a questionnaire assessing patient satisfaction with pharmacy services in general hospitals. Patient Prefer Adherence. 2014;8:371-5.

11. Al-Jumah KA, Hassali MA, Alzaagi I. Patient satisfaction with the health services provided by the pharmacist at a general hospital in Riyadh, Saudi Arabia. Eur J Pers Centered Healthc. 2014;2(4):517.

12. Ahmed Y, Pharm A, Pharm C. National Pharmacy Practice Programs at Ministry of Health in Saudi Arabia. Journal of Pharma and Pharmaceutical Science. 2015;1(2):17-8.

13. Holsclaw SL, Olson KL, Hornak R, Denham AM. Assessment of patient satisfaction with telephone and mail interventions provided by a clinical pharmacy cardiac risk reduction service. J Manag Care Pharm. 2005;11(5):403-9.

14. Alhaddad MS, Mudhish EA, Bukhari RA, Aladwani AAA, Asiri SM. Assessment of female satisfaction with the role of male community pharmacists in the Kingdom of Saudi Arabia. J Clin Diagnostic Res. 2018;6(12):FC01-5.

15. Oparah AC, Kikanme LC. Consumer satisfaction with community pharmacies in Warri, Nigeria. Res Soc Adm Pharm. 2006;2(4):499-511.

Cite this article as: Almaznai MM, Almadani OM, Aloraifi IAK, Alsallouk SA, Alkabaz H, Alotaibi AS, Alamri HA, Al-Hennawi KI, Al-Hennawi MI, Alomi YA. Assessment of Patient Satisfaction with Pharmaceutical Services in Ministry of Health Hospitals at East Province, Saudi Arabia. Int J Pharmacol. Clin. Sci. 2019;8(2):116-21. 